\title{
Application of the defect management improvement mode under Joint Commission International standard to improve the instrument cleaning and disinfection effect and management quality in the central sterile supply department: a randomized trial
}

\author{
Lingyun Yang ${ }^{1 \#}$, Qin Xun ${ }^{1 \#}$, Jie Xu ${ }^{1}$, Da Hua ${ }^{2}$ \\ ${ }^{1}$ Disinfection Supply Center, Affiliated Wuxi No. 2 Hospital of Nanjing Medical University, Wuxi, China; ${ }^{2}$ Operating Room, The Affiliated Wuxi \\ Matemity and Child Health Care hospital of Nanjing Medical University, Wuxi, China \\ Contributions: (I) Conception and design: L Yang; (II) Administrative support: D Hua; (III) Provision of study materials or patients: J Xu; (IV) \\ Collection and assembly of data: Q Xun; (V) Data analysis and interpretation: All authors; (VI) Manuscript writing: All authors; (VII) Final approval \\ of manuscript: All authors. \\ "These authors contributed equally to this study. \\ Correspondence to: Jie Xu. Disinfection Supply Center, Wuxi No. 2 People's Hospital, 68 Zhongshan Road, Wuxi 214000, China. \\ Email: XJ4344@163.com; Da Hua. Operating Room, Wuxi Maternal and Child Health Hospital, No. 48, Huaishu Alley, Wuxi 214000, China. \\ Email: 1054722362@qq.com.
}

Background: Professional, standardized, and scientific management of the disinfection supply room is the prerequisite to ensure medical quality and improve the comprehensive strength of the hospital. This study aimed to evaluate the application of the defect management improvement mode of the Joint Commission International (JCI) standard in improving the cleaning and disinfection effect as well as the management quality of instruments in the central sterile supply department (CSSD).

Methods: From January 2020 to December 2020, 32 medical staff in the hospital CSSD were divided into control and observation groups according to the random number table method, with 16 staff members in each group. The control group adopted the standardized management mode and the observation group adopted the defect management improvement mode based on the JCI standard. During the management period, we compared the disinfection effect and incidence of adverse events of the instruments and articles in the CSSD of the two groups, and evaluated the work and satisfaction of both groups of subjects. Linear correlation analysis and multiple linear regression analysis were used to determine the influencing factors of satisfaction.

Results: During the standardized management, the instruments and articles were used 611 times in the control group and 602 times in the observation group. The cleaning qualified rate, infection awareness rate, standard implementation rate, hand hygiene implementation rate, theoretical knowledge score, and practical operation ability of the observation group were significantly higher than those of the control group $(\mathrm{P}<0.05)$. The incidence of adverse events in the observation group was significantly lower compared to the control group $(\mathrm{P}<0.05)$, and the satisfaction scores of the observation group were significantly higher than those of the control group $(\mathrm{P}<0.05)$. The total satisfaction score is independently related to the training method, educational background, and professional title.

Conclusions: Adopting the defect management improvement mode under the JCI standard for CSSD is conducive to improving the cleaning effect of instruments, enhancing the work situation and job satisfaction of medical staff, and reducing the incidence of adverse events.

Trial Registration: Chinese Clinical Trial Registry ChiCTR2100053068.

Keywords: Central sterile supply department (CSSD); Joint Commission International (JCI); defect improvement; cleaning and disinfection effect; management quality 
Submitted Nov 18, 2021. Accepted for publication Dec 24, 2021.

doi: 10.21037/atm-21-6610

View this article at: https://dx.doi.org/10.21037/atm-21-6610

\section{Introduction}

The central sterile supply department (CSSD) is a key department in the hospital to control infection and ensure the quality of medical care. It is also an important place for the distribution, recycling, cleaning, disinfection, packaging, and storage of medical devices, articles, pipelines, and other facilities and equipment used in hospital medicine, education, scientific research, and nursing work. Operators are required to standardize their behavior and strictly sterilize in order to prevent cross contamination, which could result in significant harm to patients, and even cause serious nosocomial infection (1-3). Therefore, the professional, standardized, and scientific management of the CSSD is a prerequisite for hospitals to achieve sustainable development, ensure medical quality management, and improve comprehensive strength (4). The traditional concept of CSSD primarily adopts the decentralized management mode for the disinfection and cleaning of medical devices, which cannot achieve all-round and systematic coverage, and is prone to leakage. With the continuous improvement and diversified development of the hospital management mode in recent years, the centralized management mode of medical devices has been gradually applied to the device management of CSSD, forming an advanced idea.

The Joint Commission International (JCI) Accreditation Standards for Hospitals developed by the Joint Commission on Accreditation of Healthcare Organizations (JCAHO) is an internationally recognized medical service standard and represents the highest level of hospital service and management. JCAHO is composed of multiple international experts in medical treatment, nursing, administration, and public policy from all over the world. It has been guiding and evaluating medical institutions and government departments in more than 40 countries worldwide $(5,6)$. JCI certification is also recognized by the World Health Organization. JCI standards cover 368 standards and 1,033 items. Its concept is to take patients as the center and establish relevant policies, systems, and processes to the highest quality, so as to ensure the continuous quality of hospital management and establish quality standards in line with local characteristics (7). The defect management improvement mode under the JCI standard is applied to
CSSD management, which plays an important role in improving the cleaning and disinfection of devices and optimizing the hospital management system. Based on the above research, this study will investigate the role of this mode in improving the cleaning and disinfection effect and management quality of CSSD devices, so as to provide evidence-based framework for the smooth development of clinical CSSD work. We present the following article in accordance with the CONSORT reporting checklist (available at https://atm.amegroups.com/article/ view/10.21037/atm-21-6610/rc).

\section{Methods}

\section{Patient selection}

This study was approved by the Ethics Committee of Wuxi No. 2 People's Hospital (2020012) and was conducted in accordance with the Declaration of Helsinki (as revised in 2013). All participants provided informed consent. From January 2020 to December 2020, 32 medical staff in the CSSD of Wuxi No. 2 People's Hospital were divided into control and observation groups according to the random number table method, with 16 staff members in each group.

The inclusion criteria were as follows: (I) full-time CSSD staff; (II) staff who had received qualified professional infection management training and disinfection technical specifications from the National Health Department; (III) barrier-free communication; and (IV) staff that could understand the research protocol in detail and voluntarily signed the informed consent.

The exclusion criteria were as follows: (I) objects in lactation and pregnancy; (II) participants in other studies at the same time; (III) those who were required to participate in other training or needed leave during the study; and (IV) staff with a history of mental illness or neurological disease (Figure 1).

\section{Standardized management scheme}

In the CSSD, there are two full-automatic cleaning and disinfection machines, two pressure steam sterilizers, two ethylene oxide sterilizers, and two hydrogen peroxide low- 


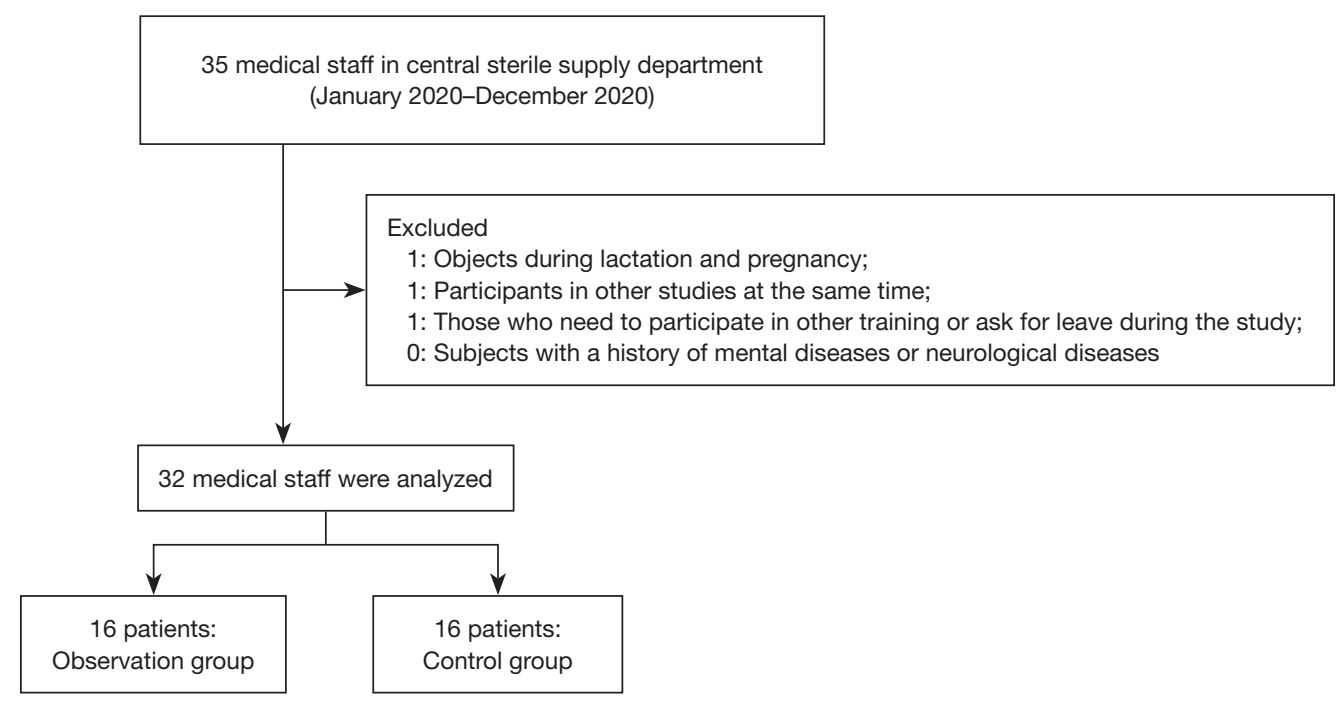

Figure 1 Research object selection flowchart.

temperature plasma sterilizers, as well as several sterile article installation and unloading equipment, pressure water gun, pressure air gun, drying equipment, packaging material cutter, ultrasonic cleaner, ultraviolet sterilizer, medical heat sealing machine, and hazardous gas environmental concentration safety detection system. The control group adopted the standardized management mode, while the observation group adopted the defect management improvement mode based on the JCI standard, and the intervention time was 2 months. The specific management measures were as follows.

\section{Control group}

Standardized management of the devices was applied, which involved the following: (I) device information entry: recording the name, code, specification, quantity, inventory, unit price, other information of key devices, as well as the information of the device package (such as code, packaging material, quantity, packaging volume, sterilization method, expiration date, etc.); (II) device recovery and counting: when CSSD submits the sterilization package, pointing out the name and quantity to confirm whether there is any damage or missing devices; (III) instrument cleaning and disinfection: using the cleaning and disinfection machines to clean and disinfect the instruments, and checking the results of cleaning and disinfection; and (IV) equipment warehousing and tracking: determining whether the sterilization requirements are met, recording the sterilization date, number, batch, personnel and other information, ensure that there are responsible personnel at each step, and establishing traceability documents (such as equipment recovery, cleaning, packaging, sterilization, and distribution records).

\section{Observation group}

(I) Establishing a steering group comprising one JCI tutor, four CSSD staff, one representative of the docking department, and one head nurse. Prior to the intervention, JCI-related training (conditional or professional training organized by JCAHO) could be conducted in advance, and field investigation, observation, and learning could be conducted in hospitals certified by JCI. After the training, theoretical and practical assessment on the JCI standard was conducted and returned to the post to participate in this study after passing the assessment.

(II) Baseline study: inviting JCI standard cognitive counseling experts to initiate baseline research according to the JCI review guidelines (8), which involved listing problems and defects one-by-one, providing targeted solutions according to each problem, and forming a baseline research investigation report. For all defective items in the report [based on the Plan, Do, Check, Act (PDCA) method (9)], analyze various influencing factors of quality problems, identifying the main causes of quality problems, conducting root cause analysis (RCA) (10), proposing and implementing solutions, and checking whether 
the implementation results meet the predetermined objectives. Furthermore, total quality management activities should also be carried out.

(III) Defect finding: this involves identifying the defects in CSSD management from the five perspectives of human, machine, material, method, and environment (based on the Six Sigma management strategy), and conducting RCA analysis. (i) Human resources: this involves investigating the composition of education and professional titles of personnel at each post, and evaluating their mastery of theoretical knowledge and professional skills of disinfection work, as well as the degree of regular training. It also involves reviewing the staff health records to determine whether there are regular physical examination arrangements, personal protection and occupational exposure risks, and ascertain whether the protection work is in place. (ii) Equipment disinfection quality: this involves identifying the defects and causes of equipment supply and management according to the links of equipment information entry, recovery, classification, cleaning, disinfection, drying, packaging, sterilization, packaging, warehousing, and distribution, etc. (iii) Material supply: this involves checking whether the disinfectant and cleaning agents are expired and whether the content is within the effective range. Moreover, the integrity of the device package, whether there is any defect, whether the label is clear and completely pasted outside the package should also be checked. (iv) Management system: this involves evaluating whether the quality management system and operational processes of the CSSD are standardized, whether the management concept and method are scientific and evidence-based, and whether there are clear and smooth operating procedures for the connection and cooperation between CSSD, the various hospital departments, and the goods supply chain management. (v) Working environment: this involves checking the clothes of medical staff meet the requirements when they are performing operations in different working areas, and ensuring that the number of bacteria in the sterile working environment meets the standards, etc.

(IV) Management strategy: (i) system specification: this involves revising the management system according to the JCI standards, which includes 30 items such as post responsibilities, operating procedures, disinfection and isolation, safety management and protection system, focusing on the quality management of disinfection and sterilization, and improving the management process. (ii) Job responsibilities: this involves defining the responsibilities of each post personnel in the department, strengthening their job responsibilities, improving their execution, and formulating relevant indicators of quality management, so as to satisfy the requirements of measurement indicators. (iii) Strengthen management: this involves uniform management by CSSD of all disinfection and sterilization instruments. The specific requirements for instrument disinfection of the infection department, operating room, and other relevant clinical departments shall also be clarified. Furthermore, the supply room shall formulate relevant requirements for external instruments and implants. (iv) Staffing: this involves reasonably allocating human resources, supplementing personnel with higher academic and clinical qualifications, adjusting the team title structure, stabilizing the talent team, and carrying out structured professional training and learning tasks. (v) Equipment management: this involves strengthening the safety management of various sterilization instruments as well as regularly performing maintenance and overhaul. Furthermore, disinfection personnel shall follow the relevant operation procedures and work with certificates. Moreover, the working area of low-temperature sterilization shall be equipped with a harmful gas concentration detection safety system, such as an automatic alarm, other detectors, etc., and set an appropriate threshold range. In case of other leakages, the emergency plan shall be immediately initiated.

(V) Quality control: the sterilization process of CSSD sterile articles adopts a combination of physical, chemical and biological monitoring, and the operation process and results meet the requirements of hospital disinfection supply center-operation specification for cleaning, disinfection, and sterilization technology. Also, the instrument cleaning results shall be checked by visual inspection. The disinfection condition should be in accordance with the hospital disinfection supply center-monitoring standard for cleaning, disinfection, and sterilization effect. The final sterilization of packaging is guided by hospital disinfection supply center packaging of final sterilized medical devices (11), which meets the relevant requirements. A questionnaire and self-examination scale shall be issued every month to report on the situation of the department, 
which shall be supervised and verified by the nursing department, and the quality management effect indicators of disinfection suppliers shall be recorded.

\section{Evaluation method}

\section{Evaluation of cleaning and disinfection effect}

The cleaning and disinfection effect of medical devices was recorded before and after CSSD standardized management, including the qualified rate of recovery, cleaning, sterilization, disinfection, and packaging.

\section{Working situation}

The working situation of medical staff before and after standardized management was compared, including the awareness of nosocomial infection, implementation of standards and hand hygiene, and evaluation of the awareness of theoretical knowledge and practical operation ability of the two groups. A self-made assessment questionnaire was used to assess the theoretical knowledge, and the contents of the standards were converted into topics. The full score is 100; the higher the score, the better the knowledge of medical staff, and the stronger the operation ability.

\section{Adverse events}

The distribution error of CSSD items were recorded during standardized management, nosocomial infection during instrument use, damage and loss of instruments and items, and the incidence of sharp instrument injury.

\section{Satisfaction evaluation}

The hospital's self-made questionnaire were issued regularly every month, and the personnel of relevant departments evaluated the job satisfaction of CSSD staff (by identifying the corresponding personnel of the satisfaction questionnaire through the document traceability system), including the integrity of the sterilization package, the integrity of the sterilization package marks, the integrity of instruments in the sterilization package, the timeliness of article delivery, the timeliness of sterile product supply, and the timeliness of rescue article supply. Each aspect was scored from 0 to 100 (across 12 aspects), including the storage of valuable or special instruments, accuracy of sterilization package distribution, storage of instruments and articles, satisfaction of department needs, service awareness, and cooperation with other departments. Higher the score were considered to indicate greater satisfaction, and the overall satisfaction was the average of 12 scores.

\section{Statistical analyses}

SPSS 22.0 statistical software (SPSS Inc., Chicago, IL, USA) was used for analysis. The counting data were expressed as the number of cases (percentage) [n (\%)], and the Chi square test was used for comparison between groups. The measurement data were expressed as the mean \pm standard deviation $(\bar{x} \pm \mathrm{s})$, and the independent data $t$-test was used for inter-group comparison. Single factor analysis and multiple linear regression were used to analyze the factors affecting the satisfaction of medical staff. $\mathrm{P}<0.05$ was considered to indicate a statistically significant difference.

\section{Results}

\section{General information}

There were two males and 14 females in the control group, aged $21-50$ years, with an average age of $36.69 \pm 7.39$ years, and working experience of $6.88 \pm 2.25$ years. Their professional titles were as follows: five nurses, six nurse practitioners, two nurse-in-charge, and one associate chief nurse. Their education levels were as follows: four technical secondary schools and below, eight junior colleges, and four colleges and above (Figure 1).

There was one male and 15 females in the observation group, aged 22-52 years, with an average age of $37.50 \pm 7.73$ years, and working experience of $6.68 \pm 2.18$ years. Their professional titles were as follows: three nurses, eight nurse practitioners, four nurse-in-charge, and one associate chief nurse. The education levels were as follows: five technical secondary schools and below, eight junior colleges, and three colleges and above.

There was no significant difference in the baseline data between the two groups $(\mathrm{P}>0.05$; Table 1).

\section{Comparison of cleaning and disinfection effect}

After standardized management, the qualified rates of recovery, cleaning, sterilization, disinfection, and packaging in the observation group were significantly higher than those in the control group $(\mathrm{P}<0.05)$, as shown in Table 2.

\section{Comparison of working situation}

The infection awareness, standard implementation, and hand hygiene implementation rates of the observation group were significantly higher than those of the control group, and the theoretical knowledge and practical 
Table 1 Comparison of baseline data between the two groups

\begin{tabular}{|c|c|c|c|c|c|c|c|c|c|c|c|}
\hline Group & \multicolumn{2}{|c|}{ Gender } & $\begin{array}{l}\text { Age (years), } \\
\bar{x} \pm \mathrm{s}\end{array}$ & $\begin{array}{c}\text { Length of } \\
\text { service } \\
\text { (years), } \bar{x} \pm \mathrm{s}\end{array}$ & \multicolumn{4}{|c|}{ Title } & \multicolumn{3}{|c|}{ Education } \\
\hline $\begin{array}{l}\text { Control group } \\
(n=16)\end{array}$ & 2 & 14 & $36.69 \pm 7.39$ & $6.88 \pm 2.25$ & 5 & 8 & 2 & 1 & 4 & 8 & 4 \\
\hline$t / \chi^{2}$ & & 368 & 0.304 & 0.239 & & & 1.167 & & & 254 & \\
\hline $\mathrm{P}$ & & .544 & 0.783 & 0.812 & & & 0.761 & & & 881 & \\
\hline
\end{tabular}

Table 2 Comparison of the cleaning effect indexes in CSSD

\begin{tabular}{lccc}
\hline Items & Control group $(\mathrm{n}=16)$ & Observation group $(\mathrm{n}=16)$ & $\chi^{2}$ \\
\hline Usage times of instruments and articles (times) & 611 & 602 & - \\
Recovery qualified rate & $478(77.91)$ & $592(98.34)$ & 19.945 \\
Cleaning qualification rate & $541(88.54)$ & $590(98.01)$ & 7.138 \\
Sterilization qualification rate & $523(85.60)$ & $582(96.68)$ & 7.600 \\
Disinfection qualification rate & $538(88.05)$ & $584(97.01)$ & 5.000 \\
Packaging qualification rate & $497(81.34)$ & $594(98.67)$ & 0.006 \\
\hline
\end{tabular}

CSSD, central sterile supply department.

Table 3 Comparison of working conditions of medical staff in CSSD

\begin{tabular}{|c|c|c|c|c|}
\hline Items & \multicolumn{2}{|c|}{ Control group $(n=16)$} & \multicolumn{2}{|c|}{ Observation group $(n=16)$} \\
\hline Infection awareness rate, $\mathrm{n}(\%)$ & $9(56.3)$ & $11(68.75)^{\mathbf{\Lambda}}$ & $9(56.3)$ & $15(93.75)^{\wedge}$ * \\
\hline Standard implementation rate, $\mathrm{n}(\%)$ & $7(43.75)$ & $12(68.75)^{\Lambda}$ & $8(50.00)$ & $15(93.75)^{\Lambda}$ \\
\hline Hand hygiene implementation rate, $\mathrm{n}(\%)$ & $9(56.3)$ & $11(68.75)^{\Delta}$ & $7(43.75)$ & $16(100.00)^{\star \star \star *}$ \\
\hline Practical operation ability, $\bar{x} \pm \mathrm{s}$ & $76.56 \pm 6.69$ & $85.94 \pm 7.89^{4}$ & $73.25 \pm 6.74$ & $91.87 \pm 7.99^{\star \star *}$ \\
\hline
\end{tabular}

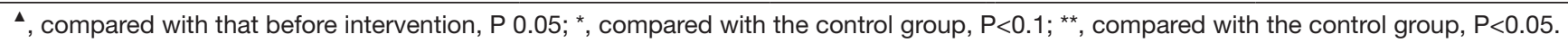
CSSD, central sterile supply department.

operation scores were also markedly higher than those of the control group $(\mathrm{P}<0.05)$, as shown in Table 3.

\section{Comparison of adverse events}

During the management period, the use times of instruments and articles in the control group were 611 times and 602 times in the observation group. Distribution error, nosocomial infection, article damage and loss, and sharp instrument injury in the control group were observed 39, 16, 46, and 31 times, respectively, and were observed seven, two, eight, and three times in the observation group. The incidence of each item in the observation group was significantly lower than that in the control group $(\mathrm{P}<0.05)$, as shown in Table 4 . 
Table 4 Comparison of the incidence of adverse events during the use of equipment in the CSSD

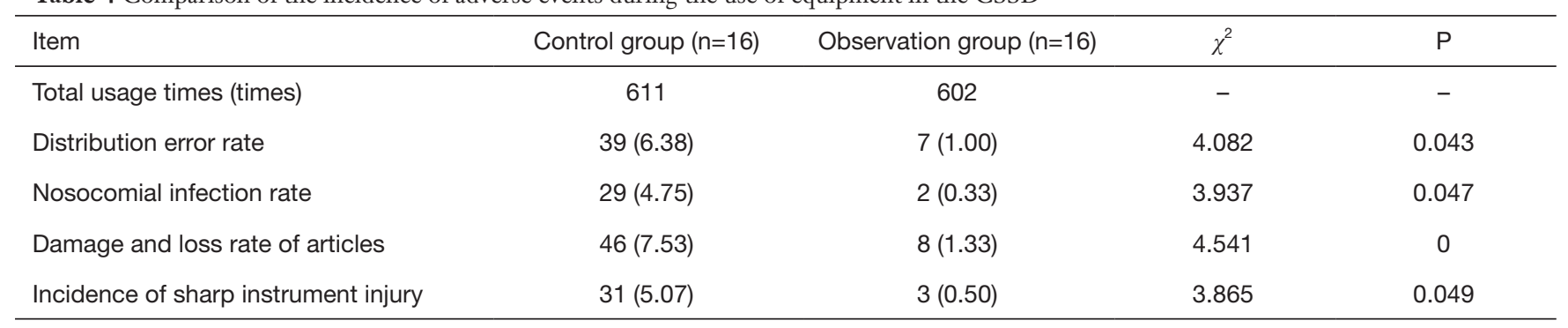

CSSD, central sterile supply department.

Table 5 Comparison of job satisfaction of medical staff in the disinfection supply room

\begin{tabular}{|c|c|c|c|c|}
\hline Items & $\begin{array}{l}\text { Control group } \\
(\mathrm{n}=16), \bar{x} \pm \mathrm{s}\end{array}$ & $\begin{array}{l}\text { Observation group } \\
\qquad(n=16), \bar{x} \pm s\end{array}$ & $\mathrm{t}$ & $\mathrm{P}$ \\
\hline Integrity of sterilization package & $76.50 \pm 8.28$ & $92.31 \pm 6.17$ & 6.125 & 0.000 \\
\hline Integrity of instruments in sterilization package & $73.31 \pm 6.57$ & $93.88 \pm 6.52$ & 8.886 & 0.000 \\
\hline Timeliness of rescue supplies & $43.56 \pm 4.40$ & $97.63 \pm 2.47$ & 42.869 & 0.000 \\
\hline Storage of valuable or special instruments & $72.13 \pm 7.69$ & $94.38 \pm 3.40$ & 10.58 & 0.000 \\
\hline Accuracy of sterilization package distribution & $73.69 \pm 7.80$ & $97.81 \pm 2.51$ & 11.784 & 0.000 \\
\hline Cooperation with departments & $67.81 \pm 5.72$ & $96.69 \pm 3.26$ & 17.547 & 0.000 \\
\hline Overall satisfaction & $70.78 \pm 2.12$ & $95.22 \pm 1.18$ & 40.352 & 0.000 \\
\hline
\end{tabular}

\section{Comparison of satisfaction}

The satisfaction of the observation group was significantly higher than that of the control group $(\mathrm{P}<0.05)$, as shown in Table 5 .

\section{Analysis of influencing factors of satisfaction}

The results of univariate analysis showed that length of service, professional title, educational background, and training mode were statistically significant $(\mathrm{P}<0.05)$, as shown in Table 6. Multiple linear regression analysis was then performed with the above markers as independent variables $\left(\alpha_{\text {in }}=0.05 ; \alpha_{\text {out }}=0.1\right)$ the total satisfaction score as the dependent variable. The factors that may affect the satisfaction, length of service, and total satisfaction scores are shown in Table 7.

\section{Discussion}

CSSD is an important department to ensure the health and safety of medical devices in hospitals. The sterilization effect is the key factor to maintaining medical safety. With the rapid development of medical technology, CSSD has also introduced advanced medical equipment and management concepts, and gradually realized the reform towards standardization, standardization, scientization, and informatization, which also requires CSSD staff to constantly master new technologies, knowledge, and skills, improve personal comprehensive ability, and further enhance the work effect and service quality $(12,13)$. The JCI standard is the guide for quality certification of medical institutions worldwide. It is based on the principles of 
Table 6 Univariate analysis of satisfaction

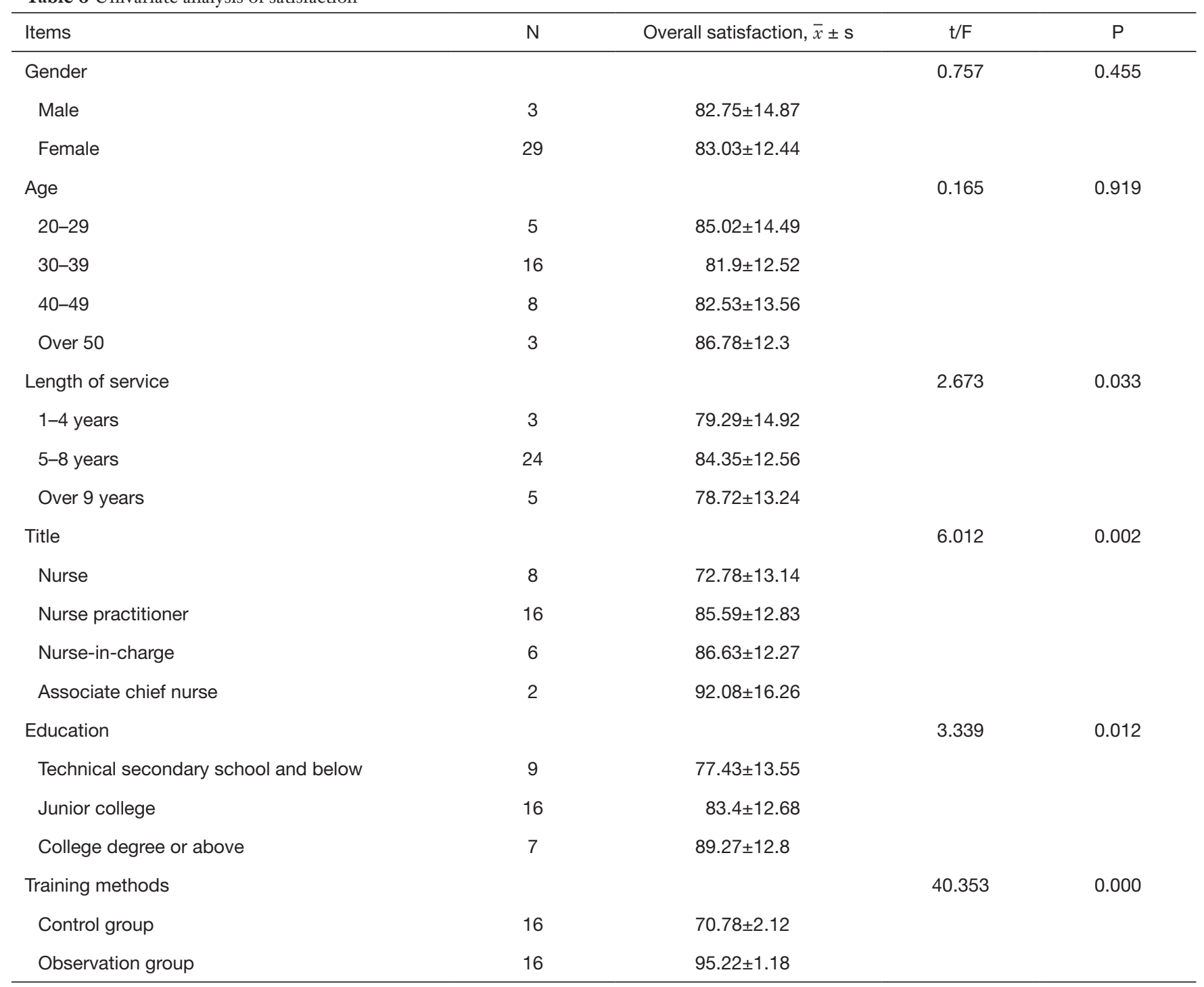

Table 7 Multivariate regression analysis of satisfaction

\begin{tabular}{lcccc}
\hline Factors & Regression coefficient b & Standard error & Standard regression coefficient & $\mathrm{t}$ \\
\hline Length of service & 0.542 & 0.184 & 0.087 & 1.579 \\
Title & 0.563 & 0.146 & 0.139 & 0.429 \\
Education & 0.113 & 0.046 & 0.098 & 0.015 \\
Training methods & 1.129 & 0.278 & 0.243 & 2.454 \\
\hline
\end{tabular}

quality management and continuous improvement to create a safe quality culture for medical institutions and obtain the optimal effect in the process of continuous improvement. The JCI standard consists of 4 parts, including 17 chapters.
The provisions related to CSSD are mainly arranged in the section of IP-SG in part II of the patient-centered standards, and 11 standards in part III; In addition, there are chapters on quality improvement and patient 
safety, governance, leadership and management, facility management and safety, information management, etc. The JCI standard not only provides an evaluation guide for the current CSSD quality management of the hospital, but also provides ways and methods for continuous improvement. In this study, the defect rectification of CSSD based on the JCI standards mainly involved "reduction of medical-related infection risk" in part II of the patient-centered standards, "infection prevention and control" in part III of the medical institution management standards, and other quality improvement chapters such as patient safety, leadership and management, facility management and safety, and information management, etc. (14). The results showed that the hospital management effect was significantly improved and the quality has been continuously enhanced.

The results of this study showed that the cleaning and disinfection effect of the observation group was markedly better than that of the control group, which demonstrated that the qualified rate of recovery, cleaning, sterilization, disinfection, and packaging was significantly higher, and the instrument unpacking, cleaning, disinfection, packaging, and environmental management were also superior $(\mathrm{P}<0.05)$. The vice president, as the supervisor CSSD director, is the first responsible person, and each connecting department shall supervise and inspect and jointly complete the rectification work. This management mode is conducive to establish JCI awareness among staff, correctly understanding errors, optimizing the process, as well as analyzing the root causes, identifying defects, and formulating targeted solutions, so as to effectively prevent errors and improve the qualification rate of each operation process $(15,16)$. In daily work, the "five regular methods" can be used to manage and maintain the working environment (17), this will ensure a sustainable improvement in the quality of CSSD instruments and equipment, and improve the professional ability and service level of the team.

In addition, compared with the control group, the infection awareness, standard implementation, and hand hygiene implementation rates of personnel in the observation group were notably higher, as were the theoretical knowledge and practical operation scores. Furthermore, the incidence of defects such as distribution error, nosocomial infection, article damage and loss, and sharp instrument injury was lower, indicating that the work situation of the observation group was superior. The reason for this is that the JCI standard not only provides evaluation standards for the current quality management of the hospital, but also provides strategies and ways for and continuous improvement. In the process of traditional standardized management, medical staff pay less attention to the JCI standard, lack relevant theoretical knowledge and practical technical basis, and have little knowledge about the focus of standard requirements (18). The steering group established in this study received professional training related to JCAHO or JCI in advance, and discipline experts were invited to attend and provide guidance. Through onsite observation and learning, it is easier for students to accept the key points of knowledge, and then teach and guide other personnel. The leading group also invited JCI standard tutoring experts to systematically train staff in the observation group in clinical practice, help medical staff to accept reforms to the management system, job responsibilities, and operation specifications, and to better integrate into new work process, standardize their own work behavior, fully implement rectifications, and ensure the seamless quality management of the whole process. Therefore, following the defect management improvements based on the JCI standard, the comprehensive strength of CSSD staff was significantly improved and the incidence of quality events was markedly reduced.

This study also showed that the job satisfaction of the observation group was higher $(\mathrm{P}<0.05)$, which was due to the JCI standard improving patient safety and service quality, as well as enhancing the core competitiveness of the hospital. The JCI standard is an internationally recognized quality standard, which creates a safe quality culture in the hospital, which can promote staff to report adverse events and safety problems in time, improve themselves, and enhance the trust of patients and the public in the quality of the hospital. This will allow for working closely with the cooperative leading group, setting the focus of the work process, leading the participation of all staff and the cooperation of all departments, establishing full control and implementation, ensuring comprehensive development of quality management, as well as more enthusiasm and coordination between staff $(19,20)$. The leading group, which was composed of the CSSD, nursing department, and other departments, formulated standardized standard operating procedures, provides detailed quantitative assessment and scoring of the department, and makes corrections and comments on site, so as to ensure that employees can significantly improve their work efficiency and satisfaction in a safe and efficient working environment.

In summary, adopting the defect management improvement mode based on the JCI standard is conducive to improving the cleaning and disinfection effect of the 
CSSD, continuously improving quality management, and improving the work effect and satisfaction of staff. This management mode is based on the internationally recognized JCI standard and has important clinical application prospects. However, the limitation of this study lies in the small sample size, which cannot avoid the impact of accidental factors on the results. Multi-center research should be carried out to investigate the root causes and treatment strategies of various quality events, and establish standardized processes to provide an evidence-based framework for the clinical promotion of this process.

\section{Acknowledgments}

Funding: None.

\section{Footnote}

Reporting Checklist: The authors have completed the CONSORT reporting checklist. Available at https://atm. amegroups.com/article/view/10.21037/atm-21-6610/rc

Trial Protocol: Available at https://atm.amegroups.com/ article/view/10.21037/atm-21-6610/tp

Data Sharing Statement: Available at https://atm.amegroups. com/article/view/10.21037/atm-21-6610/dss

Conflicts of Interest: All authors have completed the ICMJE uniform disclosure form (available at https://atm. amegroups.com/article/view/10.21037/atm-21-6610/coif). The authors have no conflicts of interest to declare.

Ethical Statement: The authors are accountable for all aspects of the work in ensuring that questions related to the accuracy or integrity of any part of the work are appropriately investigated and resolved. The study was approved by the Ethics Committee of Wuxi No. 2 People's Hospital (2020012) and was conducted in accordance with the Declaration of Helsinki (as revised in 2013). All participants provided informed consent.

Open Access Statement: This is an Open Access article distributed in accordance with the Creative Commons Attribution-NonCommercial-NoDerivs 4.0 International License (CC BY-NC-ND 4.0), which permits the noncommercial replication and distribution of the article with the strict proviso that no changes or edits are made and the original work is properly cited (including links to both the formal publication through the relevant DOI and the license). See: https://creativecommons.org/licenses/by-nc-nd/4.0/.

\section{References}

1. Warren BG, Turner N, Smith B, et al. Measuring the impact of continuous disinfection strategies on environmental burden in outpatient settings: a prospective randomized controlled trial. Open Forum Infect Dis 2020; 7:ofaa431.

2. Wei Y, Xu M, Wang W, et al. Effect analysis of PDCA cycle method applied in nursing management of disinfection supply room. Panminerva Med 2020. [Epub ahead of print]. doi: 10.23736/S0031-0808.20.03969-5.

3. Bai L, Liu S, Qiao L, et al. Effect of strengthening detail management on nursing quality and nursing satisfaction in disinfection supply room. Panminerva Med 2020. [Epub ahead of print]. doi: 10.23736/S0031-0808.20.03952-X.

4. Chang CWD, Brenner MJ, Shuman EK, et al. Reprocessing Standards for Medical Devices and Equipment in Otolaryngology: Safe Practices for Scopes, Speculums, and Single-Use Devices. Otolaryngol Clin North Am 2019;52:173-83.

5. Awan MMA, Qureshi S, Khushnood K. Joint Commission International Accreditation: A breakthrough in Pakistan. Journal of Shifa Tameer-e-Millat University 2020;3:136-7.

6. Hashemi B, Motamedi M, Etemad M, et al. An Audit of Emergency Department Accreditation Based on Joint Commission International Standards (JCI). Emerg (Tehran) 2014;2:130-3.

7. Campra M, Riva P, Oricchio G, et al. Association between Patient Outcomes and Joint Commission International (JCI) Accreditation in Italy: An Observational Study. Calitatea 2021;22:93-100.

8. Otsuki N, Shimizu A, Kamada T. Introduction of a JCI Guideline: Practical Guideline for Investigation, Repair and Strengthening of Cracked Concrete Structures. Journal of Chemistry and Chemical Engineering 2014;8:72.

9. Ariyanti FD, Russell A, Setiawan L. Vendor management system improvement using PDCA and optimizing transporter vendor selection using fuzzy analytical hierarchy process. IOP Conf Ser: Earth Environ Sci 2021;794:012077.

10. Stretton P. Beyond root cause analysis: How variation analysis can provide a deeper understanding of causation in complex adaptive systems. J Patient Saf Risk Manag 
2021;26:74-80.

11. Bi Q, Chen B. Research on Application of JCI Evaluation Standard in Hospital Infection Control and Management of Disinfection Supply Center. Smart Healthcare 2019;5:25-7.

12. Patrick A, Hess O, Cooper K, et al. Daily Disinfection of the Hospital Room and Non-critical Items: Barriers and Practical Approaches. Curr Infect Dis Rep 2020;22:1-5.

13. Anderson DJ, Chen LF, Weber DJ, et al. Enhanced terminal room disinfection and acquisition and infection caused by multidrug-resistant organisms and Clostridium difficile (the Benefits of Enhanced Terminal Room Disinfection study): a cluster-randomised, multicentre, crossover study. Lancet 2017;389:805-14.

14. Reynolds KA, Sexton JD, Garavito F, et al. Impact of a Whole-Room Atomizing Disinfection System on Healthcare Surface Contamination, Pathogen Transfer, and Labor Efficiency. Crit Care Explor 2021;3:e0340.

15. Sibal A, Uberoi RS, Malani A. An approach to improve patient safety and quality beyond accreditation. World Hosp Health Serv 2016;52:10-2.

16. Steenbruggen RA, van Oorsouw R, Maas M, et al. Development of quality indicators for departments of

Cite this article as: Yang L, Xun Q, Xu J, Hua D. Application of the defect management improvement mode under Joint Commission International standard to improve the instrument cleaning and disinfection effect and management quality in the central sterile supply department: a randomized trial. Ann Transl Med 2022;10(3):137. doi: 10.21037/atm-21-6610 hospital-based physiotherapy: a modified Delphi study. BMJ Open Qual 2020;9:e00812.

17. Xu Z, Yao A, Pan H, et al. Application effect and managerial experience of $5 \mathrm{~S}$ methodology in the operating room. Chinese Journal of Modern Nursing 2015;21:1180-2.

18. Okumura Y, Inomata T, Iwagami M, et al. Shortened cataract surgery by standardisation of the perioperative protocol according to the Joint Commission International accreditation: a retrospective observational study. BMJ Open 2019;9:e028656.

19. Pfaff H, Hammer A, Ballester M, et al. Social determinants of the impact of hospital management boards on quality management: a study of 109 European hospitals using a parsonian approach. BMC Health Serv Res 2021;21:70.

20. Wang HF, Jin JF, Feng XQ, et al. Quality improvements in decreasing medication administration errors made by nursing staff in an academic medical center hospital: a trend analysis during the journey to Joint Commission International accreditation and in the post-accreditation era. Ther Clin Risk Manag 2015;11:393-406.

(English Language Editor: A. Kassem) 